\title{
Formação pedagógica em cursos de licenciatura: um estudo de caso
}

Pedagogical formation in teaching degree courses: a case study

\author{
Mardem Michael Ferreira da Silva* \\ Universidade Federal de Viçosa
}

Mayra Cristina da Silva Costa**

Universidade Federal de Viçosa

Camila Lopes Almeida***

Universidade Federal de Viçosa

\author{
Dienny Sthefany da Silva**** \\ Universidade Federal de Viçosa \\ Pamela Carvalho Lobato***** \\ Universidade Federal de Viçosa \\ Helder Canto Resende****** \\ Universidade Federal de Viçosa
}

Resumo Na preparação para a docência em cursos de Licenciatura, a Formação Pedagógica é um componente primordial. No entanto, historicamente, essa formação é quase silenciada em relação à formação para a Área Disciplinar. Entendendo a importância da formação para a docência esse estudo teve como objetivo compreender as formas de organização da Formação pedagógica no curso de Ciências Biológicas do campus Florestal da Universidade Federal de Viçosa. Além da análise do Projeto Pedagógico de curso e da matriz curricular, foi realizada uma investigação, por meio da aplicação de questionários aos egressos do curso. Os resultados mostraram que a formação docente não é a missão primeira do curso e que as disciplinas de formação pedagógica são insuficientes para garantir a formação sólida que o professor precisa para atuar em sala de aula.

PALAVRAS-CHAVE: Formação de professores; Formação pedagógica;

Licenciatura.

Abstract In preparation for the exercise of teaching, in an initial training course for teachers is an essential component. However, it is observed that historically, this training is almost left out in relation to training for the Disciplinary Area. Understanding the importance of training for teaching and knowing its limitations in the current settings for the degree courses, this study aimed to understand the ways of the pedagogical teacher training in the course of Biological Sciences of the Forestal campus of Federal University of Viçosa. In addition to the analysis of the Pedagogical Project course and the curriculum, an investigation was made through the use of questionnaires to the graduates of the course. The results showed that the preparation for teaching is not the only focus of the course, as appointed formally as a teaching degree, and is considered to have an insufficient pedagogical formation aspect to ensure solid formation.

KEYWORDS: Teacher training; Pedagogical formation; Teaching degree. 
Mardem Michael Ferreira da Silva - Mayra Cristina da Silva Costa - Camila Lopes Almeida

- Dienny Sthefany da Silva - Pamela Carvalho Lobato - Helder Canto Resende

\section{Introdução}

A formação pedagógica oferecida pelos cursos de formação inicial de professores se faz imprescindível para auxiliar o futuro docente em sua prática. No entanto, observa-se que, ao longo da história, as disciplinas de formação específica para a área disciplinar têm recebido maior atenção e espaço nas grades curriculares em detrimento das disciplinas consideradas de formação pedagógica (Chaves, 2014, p.3).

Pesquisas apontam críticas e limitações dos cursos de licenciatura, questionando sua efetividade na formação de professores devidamente capazes de atuarem no Ensino básico (Goedert, et al., 2003; Pimenta, 1998; Gatti \& Barreto, 2009, p. 146). Segundo Malucelli (2001, p.4) além do fato de que as disciplinas específicas da área ocupam a maior carga horária do curso, as disciplinas pedagógicas ofertadas não se articulam de forma efetiva com a prática docente e com o ensino da área disciplinar.

O ideal seria que, a princípio, todas as disciplinas do curso de formação de professores fossem articuladas à prática docente. No entanto, a função de realizar essa ponte entre a área de educação e a do conteúdo específico fica a cargo das disciplinas de prática de ensino e instrumentação. Sendo que, estas ainda não são estruturadas de forma eficiente (Malucelli, 2001,p.11).

Tratando especificamente da formação inicial de professores de ciências e biologia, o que se observa são cursos com caráter dicotômico, versando entre o bacharelado e a licenciatura, onde a identidade destes como cursos de formação para a docência, muitas vezes não é considerada. Assim, o que se tem, é uma formação relevante em áreas específicas da biologia e da ciência de um modo geral, desarticulada da prática docente e das disciplinas pedagógicas em número insuficiente no curso (Malucelli, 2001, p.11). Este fato, segundo Chaves (2014, p.3), deixa clara a permanência do antigo modelo $3+1$ que, teoricamente, é tratado como já extinto.

Observando a dicotomia entre a formação pedagógica e a formação específica, sendo aquela secundarizada nos cursos de licenciatura, entende-se que isso ainda não foi superado apesar dos esforços.

Assim, tendo consciência da importância da formação pedagógica para o exercício da docência, e sabendo de suas limitações nos cursos de licenciatura, entendemos que são necessárias avaliações rigorosas quanto á formação que é oferecida aos futuros professores deste país. Nesse sentido, além da avaliação da estruturação curricular do curso, este pode ser avaliado com base na percepção dos egressos sobre a qualidade da formação que receberam (Machado, 2001, p. 47).

Diante dessa perspectiva, é que essa pesquisa foi desenvolvida, sendo o foco da mesma a formação pedagógica no curso de Licenciatura em Ciências Biológicas da Universidade Federal de Viçosa, campus UFV Florestal, situada em Florestal - MG. O objetivo principal deste estudo foi compreender e discutir as formas de organização das disciplinas de cunho pedagógico no contexto deste curso, avaliando-as, também segundo a percepção dos egressos do curso. Além disso, objetivou-nos também compreender qual a identidade do curso em questão. 


\section{Referencial teórico}

De maneira geral, a formação pedagógica de um professor, é constituída por saberes relacionados às Ciências da Educação e ao Ensino da Matéria. Essas duas categorias estão diretamente relacionadas ao processo de ensino, seja por meio da reflexão acerca da prática ou a preparação efetiva para o magistério (Chaves, 2014, p.5).

Os saberes relacionados às Ciências da Educação orientam os educadores a pensar sobre o contexto da escola, do aluno e de sua prática. Assim, esses saberes, devem ser orientados por disciplinas relacionadas às Ciências da Educação como a Psicologia da Educação, a Filosofia da Educação, a História da Educação, a Sociologia da Educação, a Antropologia da Educação, a Didática e também conteúdos relacionados às políticas educacionais e de gestão da escola (Chaves, 2014, p.6).

Aos saberes relacionados ao Ensino da Matéria como também denominado por Chaves (2014, p.6), compete-se a responsabilidade de articular o conhecimento específico da matéria a ser ensinada e o saber pedagógico e didático necessário para ensiná-la. Como seria o caso das disciplinas de Instrumentação para o Ensino e Didáticas e Metodologias específicas.

Havendo a pretensão de formar professores competentes para as escolas, é preciso que, não só os saberes específicos da área sejam articulados com a prática docente, mas que, principalmente, os saberes necessários à formação pedagógica do docente sejam incorporados de forma efetiva nos currículos dos cursos de licenciatura (Malucelli, 2001,p.12).

Sobre a formação de professores de ciências e biologia especificamente, ao investigar os problemas nos cursos que formam esses docentes, Malucelli (2001, p.11) concluiu que a falta de habilidade e profissionalização desses professores resulta, aparentemente, do fato de que as disciplinas pedagógicas oferecidas nos cursos, não são adequadas para que exerçam seu papel como mediadores entre os conteúdos específicos da matéria e os alunos.

Assim, entende-se que, as disciplinas de formação pedagógica devem contemplar aspectos que permitam entender a realidade da escola e do aluno e que permitam uma articulação entre o conhecimento específico da área e a forma sobre como ensinar esses conteúdos (Coelho, 1978 apud Malucelli, 2011, p.3).

\section{Metodologia}

Este estudo se caracteriza como uma pesquisa de caráter documental e qualitativo, onde foi analisado o curso de Licenciatura em Ciências Biológicas da Universidade Federal de Viçosa, campus UFV Florestal - MG.

Foram analisados o projeto pedagógico de curso (PPC) e sua a estrutura curricular. Além disso, para entender a percepção dos egressos a respeito da formação para a docência oferecida pelo curso, utilizamos como ferramenta a plataforma virtual SurveyMonkey, onde elaboramos um questionário eletrônico. 
A escolha pela aplicação do questionário virtual se deu devido à possibilidade de rápida obtenção de dados e um alcance maior, uma vez que vários dos egressos residem em locais distantes, assim como relatado por Rocha (2013, p.77). Constavam nesse questionário perguntas abertas e fechadas sobre a estruturação curricular do curso e também questionando sobre a significância das disciplinas pedagógicas oferecidas à formação do entrevistado enquanto professor.

\section{Coleta de dados}

A busca pelos egressos percorreu ao longo do desenvolvimento da pesquisa, entre os meses de Abril e Junho de 2016, através de redes sociais e e-mails. Ao entrar em contato com o egresso, procuramos esclarecer os objetivos da pesquisa e a importância desse tipo de estudo para a melhoria da formação docente. Após o primeiro contato, na medida em que o indivíduo manifestasse interesse em participar da pesquisa, o link do questionário era enviado via e-mail.

A listagem dos egressos do curso foi obtida no Registro Escolar da Universidade Federal de Viçosa - campus UFV Florestal, totalizando 36 indivíduos referentes às turmas que ingressaram em 2009, 2010 e 2011. Do total de egressos levantados, todos foram abordados. Destes, apenas 25 retornaram o primeiro contato, manifestando interesse em participar da pesquisa. Após o envio do questionário, obtivemos resposta de apenas 20 indivíduos.

\section{Análise e discussão dos resultados}

Para responder aos objetivos propostos no presente trabalho, buscamos entender, através da análise do Projeto Pedagógico de Curso (PPC), a identidade do curso em questão e como é tratada, neste documento, a formação pedagógica que deverá ser oferecida aos estudantes. A visão a respeito do curso, bem como sua qualidade também pode ser avaliada tendo como base a percepção de seus egressos (Machado, 2001, p.47). Então, buscamos também entrevistá-los.

$\mathrm{Na}$ fundamentação legal do PPC, é apresentada a importância das relações teóricas e práticas em todas as atividades não somente com o objetivo fundamental de formar o docente em nível superior, mas também apresentando os requisitos mínimos para o Biólogo atuar em pesquisa, projetos, análises, perícias, fiscalização, emissão de laudos, pareceres e outros serviços nas áreas de meio ambiente, saúde e biotecnologia. Tal concepção se faz contraditória quando observamos que as descrições do curso explicitam a necessidade de que os currículos próprios da Licenciatura não se confundam com o Bacharelado.

A preparação dos alunos em se tratando da formação pedagógica necessária à docência, quase não é referenciada no PPC do curso analisado. Existe a menção da formação para a docência como objetivo do curso, no entanto, não são traçadas estratégias para a formação do professor de ciências e biologia no sentido de oferecer ferramentas para o trabalho em sala de aula. Verifica-se então, a não evidência da valorização da formação docente dos alunos e que existe baixo investimento em formação para as práticas pedagógicas, uma vez que são poucas as propostas de inserção do aluno no campo educacional. 
No PPC, é declarado também que a maioria das disciplinas do curso deve possuir cunho teórico prático, compreendendo assim um total de 885 horas exclusivamente em aulas práticas, sendo que destas, 420 horas deverão ser dedicadas às práticas referentes ao ensino. Analisando então o currículo do curso, observamos que tal afirmação não condiz com as 150 horas de aulas práticas, presentes na matriz do curso, relacionadas ao ensino, pertencentes às disciplinas de instrumentação para o Ensino (Ciências, Saúde e Meio Ambiente). As demais disciplinas práticas abrangem em sua maioria caráter de formação para os conhecimentos específicos da área disciplinar. Desconsideramos aqui as horas referentes ao Estágio Supervisionado Obrigatório por entendermos que de acordo com a Resolução CNE/CP 2/2002 os cursos de licenciatura devem garantir em seus projetos pedagógicos uma carga equivalente a 400 horas de Estágio Supervisionado, a partir da segunda metade do curso.

É afirmado ainda, no PPC, o compromisso com a flexibilização da formação docente através de disciplinas optativas que permitam a exploração e abordagem de outros temas que não somente os do campo especializado. Observamos foi que dentre as vinte oito disciplinas optativas disponibilizadas na matriz curricular do curso, apenas três disciplinas possuem caráter de formação pedagógica, a saber: Concepção Filosófica da Educação, Sociologia da Educação e Dinâmica de Grupo. Em se tratando de um curso de Licenciatura, entendemos que essas disciplinas deveriam ser, em sua maioria, relacionadas a práticas docentes. A maioria das disciplinas optativas é referente ás áreas biológicas e agrárias deixando claro, ao nosso parecer, a falta de preocupação com a complementação para a formação docente do estudante.

\section{Carga horária das disciplinas relacionadas à formação peda- gógica}

A distribuição das cargas horárias das disciplinas relativas aos conhecimentos específicos de área, ocupam a maior parte da grade curricular durante a primeira metade do curso e diminui na segunda metade, que é quando são oferecidos os Estágios Supervisionados que demandam cerca de 400 horas destinadas a atividades presenciais em escolas. As disciplinas relacionadas à Formação Pedagógica são oferecidas somente a partir do terceiro período e de forma desproporcional sendo que, somente em um único período durante todo o curso são oferecidas mais que uma disciplina de caráter pedagógico.

Das 3.090 horas mínimas obrigatórias à formação no curso investigado, 405 horas são referentes aos estágios supervisionados, 120 horas às disciplinas optativas, 210 às atividades complementares e 135 dedicadas ao trabalho de conclusão de curso (TCC). Deste modo, das 2.220 horas dedicadas a disciplinas, apenas 390 horas, correspondentes a $17,7 \%$ do total, são referentes a disciplinas de formação pedagógicas. Esses dados são semelhantes aos que Gatti (2009) observou em seus estudos sobre a predominância dos conteúdos específicos da área sobre os relativos à educação e docência, nos cursos de Licenciatura em Ciências Biológicas do país. Assim, verificamos o quanto a situação é preocupante, uma vez que, o curso se trata de uma Licenciatura e muito menos da metade das disciplinas são de formação específica para a prática docente. É importante ressaltar que consideramos as disciplinas de instrumentação 
Mardem Michael Ferreira da Silva - Mayra Cristina da Silva Costa - Camila Lopes Almeida

- Dienny Sthefany da Silva - Pamela Carvalho Lobato - Helder Canto Resende

para o ensino, para a contagem das horas, como disciplinas da área de educação ainda que, no campus, elas equivocadamente pertençam ao Instituto de Ciências Biológicas e da Saúde ao invés de serem coordenadas por um departamento da área educacional.

No currículo, as disciplinas ligadas às Ciências da Educação são: Psicologia do Desenvolvimento da Aprendizagem, Didática, Educação e Realidade e Estrutura do Ensino Fundamental e Médio. Estas sintetizam e condensam discussões amplas em educação, que deveriam ser tratadas também em disciplinas como História da Educação, Filosofia da Educação, Sociologia da Educação, Antropologia da Educação, não sendo estas ofertadas no currículo de disciplinas obrigatórias.

As disciplinas relativas ao ensino da matéria são três - Instrumentação para o ensino: ciências, saúde e meio ambiente. Estas não abrangem todas as áreas relacionadas aos conteúdos que o professor de ciências e biologia poderá trabalhar em sala de aula.

\section{O caráter curricular do curso na percepção de seus egressos}

Primeiramente, os egressos foram questionados sobre em qual momento do curso se deram conta de que o foco do mesmo era o de formar professores para o ensino básico. Surpreendentes $35 \%$ não consideram que ao curso esteja voltado somente para a formação de professores. Outros 35\%, somente se deram conta desse fato a partir da metade do curso. Somente $30 \%$ entendiam o curso como formador de professores antes mesmo de iniciá-lo. Assim, 70\% dos entrevistados, aparentemente entraram no curso sem a pretensão de serem professores, uma vez que, ou não entenderam o curso como Licenciatura, ou somente perceberam esse caráter um pouco mais tarde. Isso reforça o fato de que a carreira docente não é vislumbrada e também de que não se identifica a formação de professores como missão primeira desse curso. Desta forma, entendemos que a falta de esclarecimento sobre o foco principal do curso propicia esse cenário.

Os entrevistados também foram perguntados sobre como percebem o currículo do curso, do qual são egressos. Assim, $20 \%$ afirmaram que o curso possui perfil de bacharelado, apesar de ser uma Licenciatura. Apenas 5\% do total, disseram que o curso é compatível com o objetivo de uma Licenciatura, enquanto a grande maioria (75\%), afirmou que o curso transita entre a Licenciatura e o Bacharelado, corroborando com o que diz Gatti \& Barreto (2009, p.151) sobre a estrutura curricular desses cursos. Portanto, entendemos a necessidade de um empenho em esclarecer o objetivo deste curso para que essa modalidade assuma o caráter que lhe é inerente e abandone a condição de pseudolicenciatura com personalidade "bacharelesca". Tal necessidade também foi apontada entre os entrevistados, como mostram as falas a seguir:

"[...] esse curso deveria passar por um processo profundo de análise da grade curricular, pois percebi que, mesmo sendo um curso para a formação de professores, o mesmo se direciona muito mais para as disciplinas que contemplam o universo biológico do que o educacional..." 
“[...] é necessário deixar claro que o curso é de Licenciatura [...]. Não pode ter o nome de licenciatura com $90 \%$ das disciplinas para bacharel."

"Senti falta de mais disciplinas ligadas à educação... cursei disciplinas que só ocupavam carga horária e não contribuíram para minha formação docente."

O último ponto observado sobre o caráter curricular se referiu ao conceito que os egressos atribuem ao curso enquanto Licenciatura. Assim, $45 \%$ conceituaram o curso como "Regular" e 35\% como "Bom". Enquanto 15\% afirmaram que o curso em questão é um ótimo curso para a formação de professores, apenas $5 \%$ do total, afirmaram que o curso é ruim em se tratando de seu objetivo inicial que é o de formar docentes para o ensino básico.

\section{Percepção dos egressos sobre a qualidade das disciplinas pedagógicas}

Sobre as disciplinas pedagógicas relacionadas às Ciências da Educação (Educação e Realidade Brasileira, Psicologia da Educação, Estrutura e Funcionamento do Ensino e Didática), todos os egressos as consideraram importantes para um curso de Licenciatura, no entanto, a maioria afirmou que estas não são suficientes. $\mathrm{Na}$ visão de alguns entrevistados, tais disciplinas possuem pouca carga horária em relação ao que deveria ser abordado e ainda estão desarticuladas da prática docente. Em contrapartida, alguns dos entrevistados afirmaram que, para eles, apenas essas disciplinas são suficientes. Dos egressos que atuaram em sala de aula, a maioria considerou significativa a contribuição dessas disciplinas para a sua prática, no entanto alguns afirmaram que elas pouco contribuíram por serem muito teóricas. Para uma sólida formação docente deve se buscar articulação entre a teoria e a prática, não somente nas disciplinas pedagógicas, mas também nas específicas. É nessa relação dialética entre teoria e prática, segundo Pimenta e Lima (2006, p. 12), que o processo de formação dos conhecimentos é transmitido.

As disciplinas relacionadas ao ensino da matéria (Instrumentações para o Ensino de Ciências, Saúde e Meio Ambiente) também foram questionadas. As respostas foram semelhantes às observadas no parágrafo anterior, uma vez que para a maioria dos entrevistados tais disciplinas são imprescindíveis para a formação do professor de ciências e biologia, mas não são suficientes. Alguns egressos, afirmaram ser importante a criação de instrumentações que abordassem também outros assuntos como a biotecnologia e ensino de biologia, por exemplo, uma vez que o docente formado não lecionará apenas ciências. A falta de articulação entre a teoria e a prática também foram bastante citadas. Com relação aos egressos que atuaram ou atuam em sala de aula, para alguns, essas disciplinas contribuíram significativamente para suas práticas enquanto que, para outros, a pouca carga horária e a falta de prática foram atributos que as fez pouco eficientes. Desta forma, ficou clara a instabilidade do caráter teórico-prático que deveria ser oferecido, além do fato de, estas disciplinas não serem estruturadas de forma eficiente, o que é preocupante, ainda que insuficientes, elas têm o objetivo inicial de instruir para as práticas de ensino, tão ausentes no curso. 
Entendemos então, a necessidade de uma maior abrangência dessas disciplinas com relação ao conteúdo que deverá ser trabalhado em sala de aula e da instrumentação propriamente dita que apresente ferramentas concretas para o trabalho do professor. Tal discussão pode ser observada nos fragmentos a seguir:

“[...] os trabalhos e as metodologias didáticas desenvolvidas muitas vezes só ficam no papel e nas discussões em sala de aula. O aluno não tem a oportunidade de aplicar o que desenvolveu... Isto é ruim porque o papel aceita tudo e a realidade escolar pode ser diferente [...]."

"Poderiam trabalhar mais o cenário dos alunos. Por exemplo, como levar a internet, computadores e celulares para a sala de aula e como esses equipamentos podem auxiliar no ensino de ciências."

"Acredito que as disciplinas relacionadas ao ensino de ciências[...] deveriam ser mais práticas, voltadas para a sala da aula da atualidade, mostrando as dificuldades enfrentadas pelo professor."

Os entrevistados também foram questionados sobre a discrepância existente entre a quantidade de disciplinas optativas que são voltadas para a Licenciatura e as que são específicas da área de Biologia. A grande maioria dos egressos não conhecia essas disciplinas (Concepção Filosófica da Educação, Sociologia da Educação e Dinâmica de Grupo) e muitos as consideraram necessárias à formação do professor. Alguns consideraram importante que essas disciplinas fossem obrigatórias e outros não. Nenhum dos egressos cursou essas disciplinas, pois mesmo os que conheciam não tiveram a oportunidade, uma vez que estas nunca foram oferecidas. Essa disciplinas, são consideradas por Chaves (2014, p. 15) como imprescindíveis à formação docente, portanto, deveriam ser oferecidas como obrigatórias ou pelo menos ofertadas. A ínfima disponibilidade de disciplinas optativas relacionadas à área de educação nos faz perceber a falta de preocupação que existe com relação à formação pedagógica do aluno, uma vez que o curso não oferece novas possibilidades nessa área para o licenciando. Ainda que o curso seja de Licenciatura, a formação do biólogo é mais abrangente e incentivada do que a formação do professor de ciências e biologia. Podemos perceber o que foi discutido nas falas a seguir:

"[...] eles deviam pelo menos dar o direito do aluno que se interessa (pela área da educação), ter mais opções durante a sua graduação."

"Como optativas deveriam ser oferecidas várias disciplinas na área de educação, já que o campus possui cinco licenciaturas.”

Por fim, foi aberto um espaço para que os egressos entrevistados fizessem observações as quais julgassem necessárias sendo possível refletir um pouco mais sobre o que eles pensam da formação pedagógica oferecida pelo curso em questão. Muitos se manifestaram sobre a prevalência das disciplinas específicas da área de Biologia em detrimento das pedagógicas. A identidade do curso como um curso de Licenciatura que quer formar bacharéis também foi colocada em pauta, não sendo raras as falas sobre como alguns professores do curso negligenciam a formação docente. 


\section{Considerações finais}

Em nossa percepção de acordo com os dados e documentos analisados, não identificamos como missão primordial do curso, a formação para a docência. Embora essa formação seja mencionada como objetivo do curso, não se observa claramente a preocupação com a preparação para o exercício da docência, não sendo relatadas estratégias para o desenvolvimento de competências necessárias à prática docente.

A matriz curricular do curso privilegia a formação para área disciplinar em detrimento da formação pedagógica, sendo esta condensada em disciplinas com pouca carga horária em relação ao assunto que se pretende tratar. A mesma desigualdade se observa no quadro de disciplinas optativas, sendo as da área da educação, na prática, inexistentes, pois além de poucas, não são ofertadas. Sendo assim, o curso apesar de ser nomeado como licenciatura, incentiva e oportuniza em maior grau a formação do profissional biólogo que do professor de ciências e biologia. Entendemos então, o curso, como uma pseudolicenciatura com caráter "bacharelesco".

Em se tratando da formação pedagógica oferecida pelo curso, as disciplinas existentes são extremamente importantes para a formação do professor, no entanto, insuficientes. As disciplinas relacionadas às ciências da educação possuem pouca carga horária e não abrangem aspectos filosóficos, sociológicos e antropológicos da educação; aspectos esses necessários à formação dos professores.

Apesar do fato de que, num curso de licenciatura, todas as disciplinas deveriam fazer relação com a prática de ensino, fica a cargo das disciplinas de instrumentação, relacionadas ao ensino da matéria, a responsabilidade de fazer a ponte entre o conteúdo específico de ciências e biologia e o modo sobre como ensiná-los. Essas disciplinas, no entanto, além de não tratarem de alguns assuntos inerentes ao curso, são insuficientes em carga horária e não fazem relação satisfatória entre a teoria e a prática.

Apesar das limitações da formação pedagógica oferecida pelo curso, as disciplinas da área oferecidas constituem importante experiência que contribui para a prática do professor em sala de aula.

Além de rever a estrutura curricular do curso, o que se faz urgente e necessário, a instituição precisa identificá-lo como uma Licenciatura, que tem por missão a formação para o exercício da docência. A formação pedagógica do curso precisa ser estruturada de forma a abranger as competências e saberes necessários à formação do professor fazendo relação da teoria com a prática em todas as disciplinas que não somente as relacionadas diretamente ao ensino. Assim, é necessária uma mudança nas concepções e objetivos do curso, tendo como prerrogativa a busca pela identidade docente, repensando as formas de organização da formação pedagógica oferecida ao licenciando.

Não queremos com estas palavras depreciar a qualidade do curso, que, como já relatado traz experiências importantes ao futuro docente. Objetiva-nos chamar a atenção para uma necessidade urgente de uma mudança curricular que atenda às exigências de uma formação que permita ao professor saber como lidar com os desafios da profissão no cenário da educação contemporânea. 
Mardem Michael Ferreira da Silva - Mayra Cristina da Silva Costa - Camila Lopes Almeida

- Dienny Sthefany da Silva - Pamela Carvalho Lobato - Helder Canto Resende

Finalmente, apontamos para a necessidade de novas pesquisas que investiguem a presença de programas extracurriculares de formação para o professor e o impacto destas no exercício do magistério. Outra investigação que precisa ser feita é sobre quem são e qual a formação dos professores que formam professores neste curso, uma vez que, a visão do corpo docente em relação à formação docente e sua importância, podem interferir diretamente na identidade do curso.

\section{Referências}

CHAVES, T. V. Um estudo sobre as formas de organização da formação pedagógica em cursos de licenciatura. In: Atas do X Anped Sul. Florianópolis-SC,2014. Disponível em: <http:// xanpedsul.faed.udesc.br/arq_pdf/1452-0.pdf $>$. Acesso em: 3 jun. 2016.

COELHO, M. F. Avaliação da formação pedagógica na Universidade Federal do Rio de Janeiro. Dissertação de Mestrado. UFRJ, Rio de Janeiro-RJ, 1978.

GATTI, B. A.; BARRETO, E. S. S. Professores do Brasil: Impasses e desafios. Brasília: UNESCO, 2009. p. 294.

GOEDERT, L.; DELIZOICOV, N. C., ROSA, V. L. A formação de professores de Biologia e a prática docente - o ensino de evolução. In: Atas do IV Encontro Nacional de Pesquisa em Educação em Ciências (ENPEC). Bauru-SP: ABRAPEC, 2003. Disponível em: <http://fep. if.usp.br/ profis/arquivos/ivenpec/Arquivos/Orais/ORAL012.pdf> . Acesso em: 1 jun. 2016.

MACHADO, A. S. Acompanhamento de egressos: caso CEFET/PR - Unidade de Curitiba. Dissertação (Mestrado em Engenharia de Produção). Universidade Federal de Santa Catarina, Florianópolis - SC, 2001. 134 p. Disponível em: <https://repositorio.ufsc.br/handle/123456789/81600>. Acesso em: 5 jul. 2016.

MALUCELLI, V. M. B. Análise crítica da formação dos profissionais da educação: Revisando a licenciatura em Biologia. Revista Diálogo Educacional. v.2, n.4, p.139-152, 2001. Disponível em: < file:///C:/Users/win7/Downloads/dialogo-746\%20(2).pdf>. Acesso em: 25 maio 2016.

PIMENTA, S. G. Formação de professores: saberes da docência e identidade do professor. In: FAZENDA, I. (Org.). Didática e interdisciplinaridade. Campinas: Editora Papirus, 1998, p. 161-178.

PIMENTA, S. G., LIMA, M. S. L. Estágio e Docência: diferentes concepções. Revista Poiesis, v. 3, n. 3-4, p.5-24, 2005/2006. Disponível em: <http://www.revistas.ufg.br/poiesis/article/ view/10542/7012>. Acesso em: 2 jul. 2016.

ROCHA, L. D. Avaliação do curso de licenciatura em Ciências Biológicas da Uifal-MG na perspectiva de seus egressos. Revista Profissão Docente online. Uberaba-MG, v. 13, n.28, p.7698, 2013. Disponível em: <http://www.revistas.uniube.br/index.php/rpd/article/view/568>. Acesso em: 24 maio 2016.

SANTOS, M. E. G. Elementos constitutivos do trabalho docente em uma escola pública de educação básica: prescrições, atividades e seções. Santa Maria, Programa de Pós Graduação em Educação, Tese de doutorado, 2010. Disponível em: <http://bdtd.ibict.br/vufind/Record/ UFSM_eee86a5784f9fa79dfcd7e0cca0b7e54>. Acesso em: 8 jul. 2016. 
* Licenciando em Ciências Biológicas pela Universidade Federal de Viçosa, Florestal, Minas Gerais, Brasil.

* Licencianda em Ciências Biológicas pela Universidade Federal de Viçosa, Florestal, Minas Gerais, Brasil.

**** Licencianda em Ciências Biológicas pela Universidade Federal de Viçosa, Florestal, Minas Gerais, Brasil.

**** Licencianda em Ciências Biológicas pela Universidade Federal de Viçosa, Florestal, Minas Gerais, Brasil.

****** Licencianda em Ciências Biológicas pela Universidade Federal de Viçosa, Florestal, Minas Gerais, Brasil.

******* Professor doutor da Universidade Federal de Viçosa, Florestal, Minas Gerais, Brasil.

\section{Correspondência}

Helder Canto Resende - Universidade Federal de Viçosa - Campus Florestal, Instituto de Ciências Biológicas e da Saúde. Rodovia LMG 818, Km 6 - Ciências Biológicas. Campus Universitário - CEP: 35690000 - Florestal, Minas Gerais, Brasil.

E-mail: mardemmichael@yahoo.com.br - mayracsc@hotmail.com - mila.loopes@hotmail.com - dienny. sthefany@hotmail.com - pam_lobato@hotmail.com - helder.resende@ufv.br

Recebido em 04 de agosto de 2016

Aprovado em 28 de setembro de 2016 
